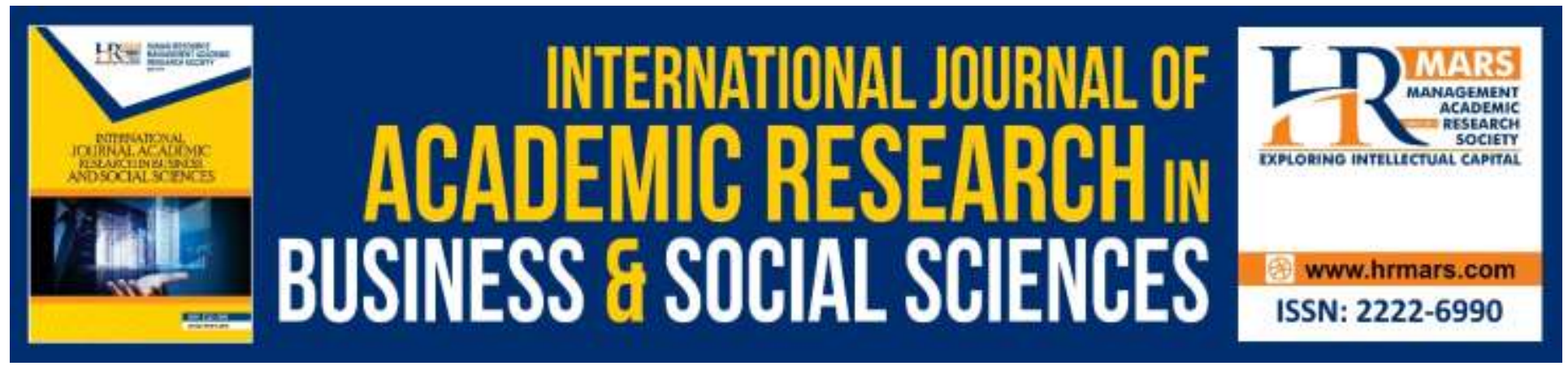

\title{
Developing a Scale to Diagnose Reading Difficulties among Primary School Students in Jordan from Teachers' Point of View
}

Halaa Freihat, Nashaat Baioumy, Roslan Ab-Rahman, Khaled Abu Sheirah, Mohammed Marshoud

To Link this Article: http://dx.doi.org/10.6007/IJARBSS/v9-i11/6537

DOI: 10.6007/IJARBSS/v9-i11/6537

Received: 10 October 2019, Revised: 27 October 2019, Accepted: 02 November 2019

Published Online: 14 November 2019

In-Text Citation: (Freihat et al, 2019)

To Cite this Article: Freihat, H., Baioumy, N., Ab-Rahman, R., Sheirah, K. A., \& Marshoud, M. (2019). Developing a Scale to Diagnose Reading Difficulties among Primary School Students in Jordan from Teachers' Point of View. International Journal of Academic Research in Business and Social Sciences, 9(11), 131-143.

Copyright: (c) 2019 The Author(s)

Published by Human Resource Management Academic Research Society (www.hrmars.com)

This article is published under the Creative Commons Attribution (CC BY 4.0) license. Anyone may reproduce, distribute, translate and create derivative works of this article (for both commercial and non-commercial purposes), subject to full attribution to the original publication and authors. The full terms of this license may be seen

at: http://creativecommons.org/licences/by/4.0/legalcode

Vol. 9, No. 11, 2019, Pg. 131 - 143

http://hrmars.com/index.php/pages/detail/IJARBSS

JOURNAL HOMEPAGE

Full Terms \& Conditions of access and use can be found at http://hrmars.com/index.php/pages/detail/publication-ethics 


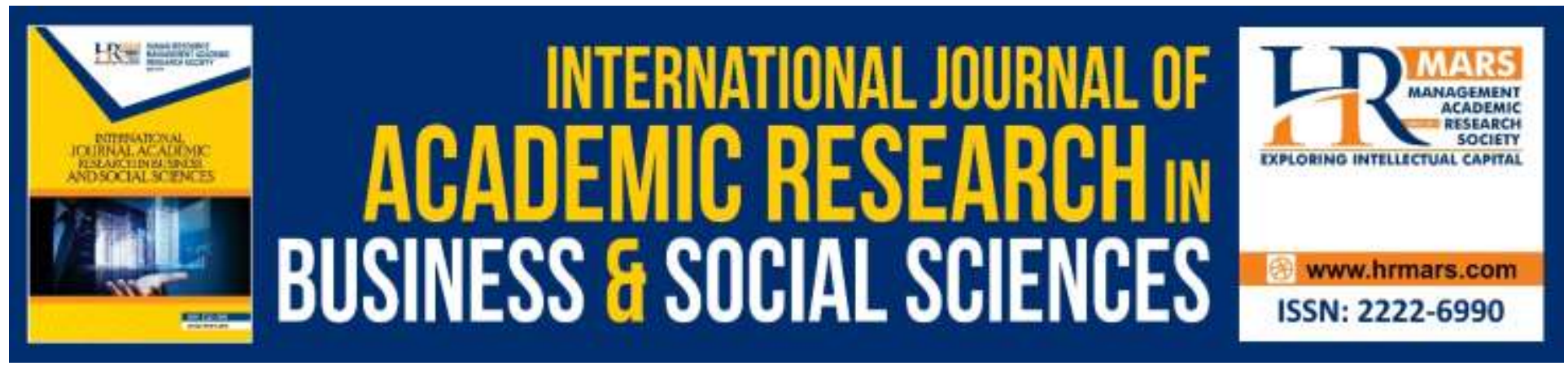

\title{
Developing a Scale to Diagnose Reading Difficulties among Primary School Students in Jordan from Teachers' Point of View
}

\section{Halaa Freihat, Nashaat Baioumy, Roslan Ab-Rahman¹, Khaled Abu Sheirah², Mohammed Marshoud ${ }^{3}$}

${ }^{1}$ Faculty of Islamic Contemporary Studies, University of Sultan Zainal Abidin, 21300, Terengganu, Malaysia, ${ }^{2}$ The preparatory Year College, Ha'el University, Saudi Arabia.

${ }^{3}$ Faculty of Arts \& Sciences, Al-Ahliyya Amman University, Jordan

\begin{abstract}
The aim of this study is to build a measure to diagnose reading difficulties among primary school students in Jordan from teachers' point of view. The study population consisted of (11513) teachers of the primary stage teachers in Jordan for the academic year (2018/2019), including (1521) male teachers and (9992) female teachers. The sample of the study comprised (484) teachers, out of them (263) male teachers and (221) female teachers. On the basis of the descriptive survey method, a questionnaire was developed to collect data. It consisted of (44) items anchored according to the Likert five-point scale. The results showed the foundations of developing a diagnostic scale for reading difficulties according to scientific bases as presented by scale One-dimensional were achieved, where the correlation coefficients between the item and the total score on the scale ranged between $(0.187-0.471)$ and all are statistically significant at the level of $(\alpha \leq 0.01)$. This is an indication of high structural validity, and the coefficient of reliability $(0.855)$, which is a very high value. The study recommended that the concerned parties should be invited to benefit from the results of the study and detecting the level of reading difficulties among primary school students and working on building remedial plans to overcome the difficulties.
\end{abstract}

Keywords: Scale Development, Diagnosing Reading Difficulties.

\section{Introduction}

Language plays an important role in the development of the child's personality, influencing his or her social relations, as well as his or her communication with others. In the case of weakness in the learning and acquisition of language, this negatively affects the personality of the child and leads to the presence of dysfunction, introversion, anxiety, fear, frustration, and a 
sense of inferiority. Hence, difficulties in language learning require a concerted effort to solve those difficulties and to understand their implications and causes (Al-Hersh, 2009).

Reading is also one of the most important ways that develop human thought; it is one of the first means of knowledge. It is also a tool for thinking, communication and self-expression, it is the source of cognitive and linguistic growth, and the key of learning, knowledge and access to Information. Therefore, it is necessary to focus on this skill, especially in the primary stages of learning and to make an effort to address the difficulties that may face the learner in reading at this stage (Abdullah et al., 1997).

Badran and Asfour (2013) define reading difficulties as a neurocognitive impairment associated with reading and spelling. People with reading difficulties have difficulty cutting words into syllables or phonemes and have trouble distributing sounds into words. The terms of reading problems and difficulties in primary school students are very diverse due to the different causes and the variety of manifestations of it and due to the different views of researchers and specialists in the approaches and theories that explain them. It also notes the multiplicity of concepts used to describe the unacceptable performance of students in reading, it may be called difficulties, problems, delays, backwardness, or dyslexia, and they are not fixed concepts. In other words, they do not fully demonstrate a specific term or description of the concept, but rather determine who uses it.

The primary stage is one of the most important stages that establish the student in all aspects of scientific, skilled and behavioral. Teachers also have a big role in detecting, diagnosing and identifying reading difficulties at this stage. It is necessary to activate the role of teachers in assisting and qualifying students with reading difficulties, and to provide tests and measures that contribute to measure the response of students in several ways to detect the sound pronunciation of words and examine the exits of letters. Then the teacher focuses on the weaknesses of the students and work to change the way of teaching until the teacher reaches the appropriate way to which he or she responds. In order to solve the problem and help pupils who suffer from it, with the adoption of the daily review of previous lessons and give him or her more texts, graded in their difficulty, to facilitate the process of pronunciation and focus on the reform of the outputs of the letters through continuous follow-up, so that he or she can read easier and better (Kandour, 2017).

The researcher believes that the standards play a key role in the lives of students in all stages of education, and based on the results determine their future, and make many decisions against them. Scales are one of the oldest and most widely used measurement and evaluation tools used by educational specialists. A scale is able to provide accurate and useful information about pupils, so that it provides many interested people such as parents of students and the Ministry of Education and workers in the areas of psychological and educational measurement and special education specialists with the aspects of the strengths and weaknesses of students.

The aspects of reading difficulties are determined by the child's loss of reading skills such as:

1) Interpreting the symbols of words, pronouncing words as one unit, understanding the meanings of words, understanding the meanings and syntax of sentences and providing the necessary vocabulary for reading. 
2) Identifying the shape of the letter according to its location in the word (example: point to the letter $\mathrm{H}$ in the word presented before you: House).

3) Signifying the separate letters in the word (example: Pronounce the word: Back).

4) Determining the sentence accurately in the words (Example: analyze the sentence into words - Mohammed went to the market).

5) Analyzing words into sounds (example: Sh / R / B).

6) Forming words of several letters (example: form the letters presented before you a meaningful word (example: $t / r$ / e / e).

7) Reading text without substitution or deletion in the letters of the words or in the line (example: read the word Tab word Bat).

8) Understanding the meaning of the sentence or paragraph (example: the student read the sentence or text and then answers questions of understanding and comprehension).

\section{Statement of the Problem}

Reading difficulties are one of the most common types of learning disabilities among primary school students in Jordan. It has been noted that there is considerable debate among researchers and practitioners in the educational field about how best to diagnose and teach students who have problems or reading difficulties (e.g., Qashqoush and Jamal, 2016). For this reason, the difficulties of reading in terms of diagnosis and treatment of pupils received special attention by researchers, educators and specialists in the fields of special education and psychology as well as measurement and evaluation in particular (Shelby, 2017).

Hence the necessity of conducting the current study to the extent of its ability to contribute to building a measure of diagnosis of reading difficulties among primary school pupils in Jordan from the point of view of teachers. Thus, the proposed measure contributes to the identification of the nature of reading difficulties in pupils at the basic stage and how to diagnose these pupils, its effectiveness in identifying the difficulties of reading among students of the primary stage, due to the seriousness of these difficulties in addition to their negative effects on the social and psychological aspects. So that the scale has a high degree of objectivity, validity and reliability in measuring the attribute that should be measured.

Therefore, the study seeks to answer the following questions:

1) What are the procedures for developing a scale to diagnose reading difficulties among primary school students in Jordan from the teachers' point of view?

2) To what extent is the scale of diagnosis of reading difficulties among primary school students in Jordan from the teachers' point of view valid and reliable?

3) What is the extent to which one-dimensional (factor analysis) is achieved in the scale of diagnosis of reading difficulties among primary school students in Jordan from the teachers' point of view?

\section{Objectives of the Study}

The main objective of this study is to develop a scale to diagnose reading difficulties among primary school students in Jordan from the teachers' point of view, through achieving the following sub-objectives: 
1) Presentation of the procedures for developing a scale to diagnose reading difficulties among primary school students in Jordan from the teachers' point of view.

2) Achieving the significance of validity and reliability of the scale of diagnosing reading difficulties among Jordanians from the teachers' point of view.

3) Detecting the one-dimensional verification (factor analysis) in the scale of diagnosis of reading difficulties among primary school pupils in Jordan from the teachers' point of view.

\section{Importance of the Study}

The theoretical significance of the present study is to highlight how to construct a scale in general and a scale to diagnose reading difficulties in particular, following precise methodological steps in developing the items of the scale according to the Likert five-point scale. So that the scale is highly effective and efficient in terms of psychometric properties of its items, which will contribute to the development of methods and tools to diagnose reading difficulties. The empirical importance of the study stems from its identification of the class covered in the study (basic education), which should receive comprehensive and full attention by the Arab studies, especially reading difficulties, by providing a measurement tool that contributes to the diagnosis of reading difficulties, considering that primary school students are the most affected group in this society. Many researchers see learning disabilities as the main cause of school failure. The percentage of pupils with reading difficulties is as high as $85 \%$ of the student population with learning disabilities (Suleiman, 2010).

\section{Study limitations}

1. Objective limits: The study was limited to develop a scale to diagnose reading difficulties among primary school pupils in Jordan from the teachers' point of view.

2. Time limits: The study was limited to the academic year (2018/2019).

3. Spatial limits: The study was limited to a sample of teachers of the primary stage in the Hashemite Kingdom of Jordan, which consists of (13) governorates.

\section{Operational Definitions}

1. Developing a scale: It is known procedurally as carrying out a set of procedures and processes aimed at developing a set of items whose main focus is diagnosis of reading difficulties.

2. Reading difficulties: Procedurally defined as disorders in the process of linguistic processing of letters, words and sentences both in terms of attention or understanding and understanding, which is centered on (deletion, addition, replacement, repetition, and reverse errors, change the location, spelling, frequency, fast reading and slow, Non-correlation of words, inappropriate reading expressions).

\section{Previous Studies}

Qashqoush, Ibrahim and Al-Jamal, Asmaa (2016) conducted a study aimed at checking the psychometric characteristics of the reading difficulties in children. On a sample of (150) children and their children were selected from Osama Bin Zaid Primary School, including (73) males and 
(77) girls aged (5-8) years. Where the descriptive method was used in the study, and applied the measure of reading difficulties prepared by the researcher (2014). The results of the study found that the scale of reading difficulties has a high degree of validity and reliability, which indicates the validity of use in the Arab environment.

Mahmoud (2012) conducted a study aimed at identifying the difficulties of reading comprehension experienced by sixth grade students in girls-friendly schools. As well as the effectiveness of the strategies of modeling and summarization in the treatment of difficulties in reading comprehension, and reduce the anxiety of reading among these pupils. The study sample consisted of (21) students, where the researcher used the descriptive and semi-experimental methods. The researcher applied a list of reading comprehension skills, a diagnostic test to identify reading comprehension difficulties, as well as a guide to using modeling and summarization strategies to address reading comprehension difficulties and reduce reading anxiety. The results of the study found the effectiveness of modeling and summarizing strategies to address the difficulties of reading comprehension and reduce reading anxiety among sixth grade students in girls-friendly schools.

Al-Duwairi (2004) conducted a study aimed at building a scale for diagnosing learning disabilities in fields of reading, writing and cognitive processes. The study was applied to a sample of students with learning difficulties in the fourth primary grade enrolled in resources rooms, which consisted of (56) male and female students from regular students. The researcher used the Kaufman intelligence test and a diagnostic test for learning difficulties as a pre-measurement. The results of the study found that the performance of students with learning disabilities was low compared to ordinary pupils.

It is clear from previous studies that the issue of developing a scale to diagnose reading difficulties is a very important topic because it has many benefits for workers in the fields of special education, measurement, evaluation, counseling and mental health diagnosis of individuals with these difficulties; it saves effort, time and material competencies. This is the result of the high degree of accuracy and objectivity in measuring the attribute to be measured, such as the study Qashqoush and Jamal (2016), which examined the verification of psychometric characteristics of the scale of reading difficulties.

It is noteworthy that there is a dearth of studies on developing a scale for diagnosing reading difficulties, which gives great importance to the topic addressed in the lives of workers in the areas of practical reading difficulties. The study aims at a highly valid tool in diagnosing reading difficulties among the students of the basic stage of the scarcity of the Arab and Jordanian environment specifically for such a scale.

\section{Study Methodology \\ Study Method}

The researcher used the descriptive survey method, which is one of the most used methods in such studies, using the questionnaire as a tool to collect the necessary data. 


\section{Study Population and Sample}

The study population consisted of all teachers of the primary stage in the Hashemite Kingdom of Jordan, which consists of (11513) teachers. The sample of the study consisted of (484) teachers of the primary stage in the Hashemite Kingdom of Jordan in the grades (first, second, third and fourth). They were randomly selected, including (263) teachers and (221) teachers.

\section{Study Instrument}

The researcher designed the tool of study, which is named developing a scale to diagnose reading difficulties among primary school pupils in Jordan from the perspective of teachers. This was done by reviewing a set of studies related to how to build the scales. Likert gradient was used so that the total score on the scale ranges between (44-220).

\section{Validity of the Scale}

Validity refers to whether a prepared scale measures what is set to measure and does not measure anything else. The validity of the scale was verified in the current study using the validity of the content, by presenting the study tool to a group of (12) experts in the same filed in order to take their opinion on the tool that was developed in terms of its suitability to the target to be measured, accuracy, formulation, language, clarity and lack of directive signals.

\section{Scale Correction Method}

The study instrument consisted of (44) items. A five-point Likert scale was used so that the total score on the scale ranges from (44 -220), where the grades on the items are given as follows: (1) strongly disagree, (2) disagree, (3) medium, (4) agree, (5) strongly agree.

\section{Results}

Frequencies and percentages were extracted in order to identify the distribution of sample by sex, educational qualification, governorate and years of experience. Table (1) shows the distribution of the sample by sex, number of years of experience, educational qualification and governorate. It is clear that the percentage of males in the sample was $54.3 \%$, which was the highest according to the sex of the sample, while the highest percentage of the number of years of experience for individuals who had more than 15 years of experience was $49.6 \%$. Individuals with a bachelor's degree achieved the highest percentage at the level of scientific qualification at $76.2 \%$. Finally, at the governorate level, the northern governorates occupied the highest percentage, which reached $37.6 \%$. 
Table 1. Distribution of participants in terms of demographic characteristics

\begin{tabular}{|c|c|c|c|c|c|c|c|}
\hline Variable & Category & $\begin{array}{c}\text { Frequenc } \\
\mathrm{y}\end{array}$ & $\begin{array}{c}\text { Percenta } \\
\text { ge }\end{array}$ & Variable & Category & $\begin{array}{c}\text { Frequenc } \\
y\end{array}$ & $\begin{array}{c}\text { Percenta } \\
\text { ge }\end{array}$ \\
\hline \multirow{3}{*}{ Sex } & Male & 236 & 54.3 & \multirow{4}{*}{$\begin{array}{c}\text { Educatio } \\
\text { nal } \\
\text { qualificat } \\
\text { ion }\end{array}$} & Bachelor & 339 & 76.2 \\
\hline & Female & 221 & 45.7 & & $\begin{array}{c}\text { High } \\
\text { diploma }\end{array}$ & 75 & 15.5 \\
\hline & Total & 484 & 100 & & Master & 40 & 8.3 \\
\hline \multirow{5}{*}{$\begin{array}{c}\text { Years of } \\
\text { Experien } \\
\text { ce }\end{array}$} & $1-5$ years & 20 & 4.1 & & Total & 484 & 100 \\
\hline & $\begin{array}{c}\text { More } \\
\text { than } 5- \\
10 \text { years }\end{array}$ & 111 & 22.9 & \multirow{4}{*}{$\begin{array}{c}\text { Governo } \\
\text { rate }\end{array}$} & South & 123 & 25.4 \\
\hline & $\begin{array}{l}\text { More } \\
\text { than } 10- \\
15 \text { years }\end{array}$ & 113 & 23.3 & & Middle & 179 & 37.0 \\
\hline & $\begin{array}{c}\text { More } \\
\text { than } 15 \\
\text { years } \\
\end{array}$ & 240 & 49.6 & & North & 182 & 37.6 \\
\hline & Total & 484 & 100 & & Total & 484 & 100 \\
\hline
\end{tabular}

\section{Results of Question 1}

In terms of question 1 "what are the procedures for developing a scale to diagnose reading difficulties among primary school students in Jordan from the teachers' point of view?" The researcher has followed the following procedures to develop her study tool to diagnose reading difficulties among primary school students in Jordan from the teachers' point of view:

1) Determining the purpose of the study instrument (the scale): It contains the measure of diagnosis of reading difficulties on paragraphs with acceptable psychometric characteristics.

2) Writing the items of the study tool (the scale): The items were written based on a set of questionnaires on how to develop a scale to diagnose reading difficulties and theoretical literature related to the study. a total of 40 items had been written covering the domains of the study, and took into account during the writing of the items bases written in terms of free from linguistic errors or written in the form of the past or negation or that the items holds two ideas or the use of words such as (often, always, ...).

3) Presenting the study instrument (the scale) to a panel of experts: after writing the items of the study instrument (the scale) was presented to a group of a panel consisting of (12) academics in order to ensure the validity of the content.

4) Reviewing and revising the items and writing them in their final form: after reviewing the observations of the experts, the researcher amended and revised the items where necessary. The final number of items was (44) items.

5) Designing an electronic version of the study tool: after writing the final version of the study tool, the researcher designed the study tool (scale) electronically through (Google drive) and formed a link to the response. 
6) Applying the test to the experimental sample and collect and correct responses: after writing the final version of the study tool (the scale) the researcher has determined the location (all the governorates of the Hashemite Kingdom of Jordan) and the application time $(24 / 4 / 2019-1 / 6 / 2019)$ to ensure accuracy and seriousness in answering the scale.

7) The researcher uploaded an Excel file for teachers' responses at the end of the application, which lasted for 4/6/2019.

8) The researcher prepared the responses to be included in the statistical programs that are able to read the data for statistical analysis to obtain the results related to the application of the responses of individuals to the items of the scale.

\section{Results of Question 2}

Question 2: what are the implications of validity and reliability for the measurement of diagnosis of reading difficulties among primary school students in Jordan from the teachers' point of view?

\section{Validity}

The researcher examined the structural validity by verifying the finding of the correlation coefficient between the items and the total score of the final version of the diagnostic measure of reading difficulties.

Table 2. Pearson correlation coefficients ( $r$ ) between the items and the overall score of the final version of the reading diagnostic

\begin{tabular}{|c|l|c|}
\hline No. & \multicolumn{1}{|c|}{ Items } & $\mathbf{r}$ \\
\hline 1. & Deletes certain letters or syllables from the word & $0.187^{* *}$ \\
\hline 2. & Delete some words from the sentence & $0.243^{* *}$ \\
\hline 3. & Adds some letters or syllables that are not in the word & $0.341^{* *}$ \\
\hline 4. & Adds some words that are not in the sentence & $0.436^{* *}$ \\
\hline 5. & Replaces a word with another word when reading in a single sentence & $0.428^{* *}$ \\
\hline 6. & $\begin{array}{l}\text { Replaces a character with another character when reading in a single } \\
\text { sentence }\end{array}$ & $0.385^{* *}$ \\
\hline 7. & Repeats a specific word in the text if it stops during reading & $0.447^{* *}$ \\
\hline 8. & Changes the position of letters in a word & $0.424^{* *}$ \\
\hline 9. & Some words are spelled incorrectly & $0.442^{* *}$ \\
\hline 10. & Spells all words incorrectly & $0.471^{* *}$ \\
\hline 11. & Hesitates to read when he reaches words he does not know & $0.436^{* *}$ \\
\hline 12. & Reads quickly with the inability to perceive the correct understanding & $0.369^{* *}$ \\
\hline 13. & Reads incorrectly & $0.308^{* *}$ \\
\hline 14. & Deletes words that he can't pronounce quickly while reading it & $0.367^{* *}$ \\
\hline 15. & Reads very slowly so that he can recognize and read the symbols of words & $0.309^{* *}$ \\
\hline 16. & $\begin{array}{l}\text { Reads very slowly making him unable to understand the meaning of the } \\
\text { text and losing its structure }\end{array}$ & $0.373^{* *}$ \\
\hline 17. & Reads the text word by word without linking them in a single sentence & $0.398^{* *}$ \\
\hline
\end{tabular}


INTERNATIONAL JOURNAL OF ACADEMIC RESEARCH IN BUSINESS AND SOCIAL SCIENCES Vol. 9, No. 11, November, 2019, E-ISSN: 2222-6990 @ 2019 HRMARS

\begin{tabular}{|c|c|c|}
\hline 18. & $\begin{array}{l}\text { Stops too much during reading so that it doesn't stop and leads to loss of } \\
\text { meaning }\end{array}$ & $0.421 * *$ \\
\hline 19. & $\begin{array}{l}\text { It is difficult for him to read the words with a tide and understand their } \\
\text { meaning }\end{array}$ & $0.432 * *$ \\
\hline 20. & Having difficulty recognizing and reading words with static syllables & $0.357 * *$ \\
\hline 21. & It is difficult for him to read words that require proper pronunciation & $0.318^{* *}$ \\
\hline 22. & It is difficult for him to read words that contain a doubled letter & $0.310 * *$ \\
\hline 23. & Unable to recognize and read words beginning with Al Lam Ashamsia & $0.303^{* *}$ \\
\hline 24. & $\begin{array}{l}\text { Unable to identify and read words starting with Al Lam Alqamaria or } \\
\text { Ashamsia }\end{array}$ & $0.261 * *$ \\
\hline 25. & Confuses similar words in letters & $0.266^{* *}$ \\
\hline 26. & He finds it difficult to read the word in the light of its soundtracks & $0.359 * *$ \\
\hline 27. & Having difficulty integrating parts of the word & $0.419 * *$ \\
\hline 28. & He finds it difficult to visualize letters and words & $0.427^{* *}$ \\
\hline 29. & Unable to associate written code with spoken sound (within sentence) & $0.399 * *$ \\
\hline 30. & Mistakes words while reading & $0.432 * *$ \\
\hline 31. & It is difficult for him to repeat what he read with better quality & $0.397^{* *}$ \\
\hline 32. & He reads without understanding and realizes what he reads & $0.392 * *$ \\
\hline 33. & Inability to translate the sounds he hears into semantics and meanings & $0.389 * *$ \\
\hline 34. & It is difficult to observe punctuation during reading & $0.391 * *$ \\
\hline 35. & He has problems pronouncing character exits & $0.341^{* *}$ \\
\hline 36. & $\begin{array}{l}\text { He cannot distinguish between Al Yaa Al mamdodah and Al Yaa Al } \\
\text { Maqsourah }\end{array}$ & $0.358 * *$ \\
\hline 37. & $\begin{array}{l}\text { He does not distinguish between Al Taa Al Maftuhah and Al Taa Al } \\
\text { Marbutah }\end{array}$ & $0.357^{* *}$ \\
\hline 38. & He finds it difficult to observe the internal details of the word (Bab, Tab) & $0.440 * *$ \\
\hline 39. & He finds it difficult to grasp the main idea of the text & $0.381^{* *}$ \\
\hline 40. & Having difficulty extracting meanings from the readable text & $0.435 * *$ \\
\hline 41. & $\begin{array}{l}\text { He finds it difficult to distinguish the meanings of synonyms, opposites and } \\
\text { strange words }\end{array}$ & $0.382 * *$ \\
\hline 42. & He finds it difficult to form a useful sentence of several words & $0.357^{* *}$ \\
\hline 43. & He finds it difficult to complete a sentence of words given to him & $0.345^{* *}$ \\
\hline 44. & It is difficult to reproduce the meaning of a text after reading it correctly & $0.337^{* *}$ \\
\hline
\end{tabular}

Table 3 shows that the correlation coefficients between the item and the total score on the diagnostic scale of reading difficulties ranged between $(0.187-0.471)$. All items on the scale were statistically significant at the level of significance (0.01). This is an indication that the scale has high structural validity indicators that indicate its suitability to measure what is set to measure the diagnosis of reading difficulties.

\section{Reliability}

The significance of the reliability of the internal consistency of the study tool was estimated using Richardson equation (20) where the value of the coefficient of reliability (0.855) which is very high. This reflects the suitability of the tool and its suitability for the purpose of the study. 


\section{Results of Question 3}

Question 3: How far is the achievement of unidimensionality (factor analysis) in the measurement of diagnosis of reading difficulties among primary school students in Jordan from the teachers' point of view? The researcher verified the unidimensionality of the scale of diagnosis of reading difficulties among primary school students in Jordan in the Hashemite Kingdom of Jordan, by applying it to a sample of (484) teachers, using factor analysis after verifying the conditions of its use.

Table 3. The results of the global analysis of the measure of diagnosis of reading difficulties among primary school students in Jordan

\begin{tabular}{|c|c|c|c|c|c|}
\hline Factor & Eigenvalues & $\begin{array}{c}\text { Explained } \\
\text { Variance }\end{array}$ & $\begin{array}{c}\text { Cumulative } \\
\text { Variance }\end{array}$ & $\begin{array}{c}\text { First } \\
\text { Eigenvalue / } \\
\text { Second } \\
\text { Eigenvalue }\end{array}$ & $\begin{array}{c}\text { (First Eigenvalue - } \\
\text { Second Eigenvalue) / } \\
\text { (Second Eigenvalue - } \\
\text { Third Eigenvalue) }\end{array}$ \\
\hline 1 & 6.306 & 14.331 & 14.331 & 2.255 & 11.417 \\
\hline 2 & 2.797 & 6.356 & 20.688 & 1.123 & 0.981 \\
\hline 3 & 2.490 & 5.658 & 26.346 & 1.144 & 5.749 \\
\hline 4 & 2.176 & 4.946 & 31.292 & 1.026 & 0.469 \\
\hline 5 & 2.122 & 4.822 & 36.114 & 1.058 & 0.543 \\
\hline 6 & 2.006 & 4.559 & 40.673 & 1.119 & 8.454 \\
\hline 7 & 1.792 & 4.073 & 44.746 & 1.014 & 0.110 \\
\hline 8 & 1.767 & 4.016 & 48.761 & 1.150 & 1.365 \\
\hline 9 & 1.536 & 3.491 & 52.253 & 1.179 & 1.533 \\
\hline 10 & 1.302 & 2.960 & 55.213 & 1.151 & \\
\hline 11 & 1.131 & 2.571 & 57.784 & 1.110 & \\
\hline 12 & 1.020 & 2.317 & 60.101 & & \\
\hline
\end{tabular}

It is noted from Table 3 that the factor analysis by the method of the basic components has retained (12) factors whose eigenvalues are higher than (1), which explained $(60.101 \%)$ of the variation in the response on the scale. The table shows indicators that achieve the unidimensionality assumption of the diagnostic measure of reading difficulties among primary school students in Jordan. According to four indicators of unidimensionality, where three indicators were supported. The first indicator, which is assumed that the value of the explained variance on the first component should be higher than (20\%). The indicator was not met since the percentage was (14.331\%). The second indicator is that the product of the first eigenvalue divided by the second eigenvalue should be higher than (2). The indicator was accepted since the result was (2.255) as shown in figure 1 . The third indicator is that the sum of the first eigenvalue abstracted from the second eigenvalue divided on the sum of the second eigenvalue abstracted from the third eigenvalue should be greater than 7 . The indicator was accepted since the value was (11.417). The fourth indicator is that the value of the total explained cumulative variance on all components is higher than (54\%); it was (60.101\%) (Hattie, 1985). 
Figure 1. The distribution of the eigenvalue of the diagnosis of reading difficulties among the primary school students in Jordan

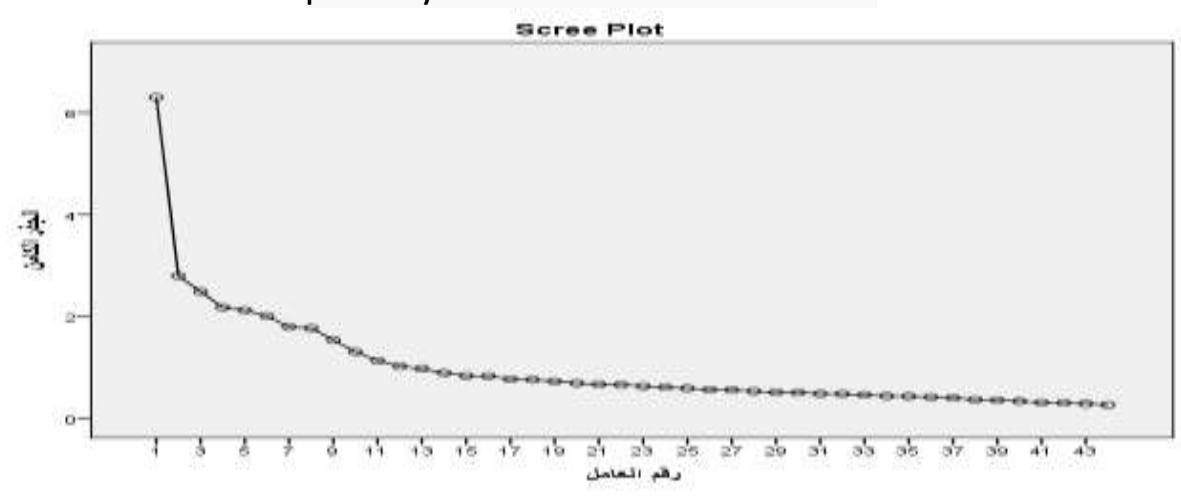

\section{Results Discussion}

The results of the study showed that the procedures of developing the scale are achieved according to the literature. The researcher attributes this result to the general foundations of developing scales. Any researcher who aims to develop a scale must follow the same procedures followed by the researcher. The researcher attributes the significance of validity and reliability to the strength of her tool used in the study, which she built based on her extensive knowledge of theoretical literature and previous studies in the same field.

The results of the study showed that the assumption of unidimensionality was achieved in the diagnosis of reading difficulties in primary stage pupils in Jordan, which consisted of (44) items, after verifying the conditions of using factor analysis, where (12) factors were retained with eigenvalues higher than (1), which accounted for $60.101 \%$ of the variance in response on the scale. Out of the indicators required to achieve the unidimensionality assumption, three indicators were supported.

The researcher attributes unidimensionality verification to the fact that the scale measures one characteristic, reading difficulties, and the scale has a high degree of accuracy in terms of diagnosing reading difficulties, and this result is not consistent with the studies previous studies.

\section{Conclusion and Recommendations}

1) This study can help the concerned parties to benefit from the results of the study and detecting the level of reading difficulties among primary school students and working on building remedial plans to overcome the difficulties.

The study Recommends:

2) Conducting further studies using the scale to make sure of validity of interpretation and the extent of its conduct with objectivity, reliability and the consistency in measuring the Attribute studied, working on further studies using different samples of individuals which are specialist in Certain difficulties from reading difficulties. The concerned authorities are invited to benefit from the results of the study and disseminate the scale to the relevant individuals in order to use it in diagnosing reading difficulties among primary school students. 
3) The concerned authorities are called for revealing the level of reading difficulties among the students of the basic stage and building remedial plans to overcome the difficulties.

\section{References}

Al-Mutairi, K. (2007). The effect of the text and its teaching in accordance with the questioning strategy on the level of reading comprehension and the tendency towards reading among people with learning difficulties from primary pupils in the State of Kuwait. Unpublished Master Thesis, College of Graduate Studies, Arabian Gulf University, Kingdom of Bahrain.

Badran, A. I., and Asfour, Q. N. (2013). Academic learning disabilities: Description and treatment. First edition. Dar Al Fikr Publishers and Distributors. P. 18-25.

Hattie, J. (1985). Methodology review: Assessing unidimensionality of tests and items. Applied Psychological Measurement, 9, 139-164.

Hersh, J. (2009). The Effectiveness of a concurrent multisensory educational program in developing reading skills for Dyslexic students in primary stage in Jordan. Unpublished doctoral thesis, Amman Arab University, Jordan.

Kandour, M. (2017). The Effectiveness of a problem solving program in rehabilitation of reading performance among students with learning difficulties: A field study on a sample of fourth and fifth year elementary students. Unpublished doctoral thesis, University Mohamed Lamine Debaghine -Setif2, Algeria.

Mahmoud, A. (2012). The Effectiveness of modeling and summarizing strategies in treating difficulties in reading comprehension and reducing reading anxiety in studies of girl-friendly schools. International Journal of Educational Research, 31, 219-258.

Qashqoush, I. and Jamal, A. (2016). Psychometric characteristics of the scale of reading difficulties among children. Journal of Scientific Research in Education, 17, 173-186.

Shalabi, A. (2017). Design of a test for the detection of dyslexia for primary school children in the province of Tlemcen. Unpublished doctoral thesis, University of Abi Bakr Belkaid, Tlemcen, Algeria.

Suliman, A. (2010). Psychology of learning disabilities: Scholarship between development and exclusion. Dar El Wafaa for Printing \& Publishing, Alexandria, Egypt. 